Article

\title{
The Establishment and Rapid Spread of Sagittaria Platyphylla in South Africa
}

\author{
Mpilonhle S. Ndlovu ${ }^{1, *}$, Julie A. Coetzee ${ }^{1}$, Menzi M. Nxumalo ${ }^{2}$, Reshnee Lalla ${ }^{2}$, \\ Ntombifuthi Shabalala ${ }^{2}$ and Grant D. Martin ${ }^{3}$ \\ 1 Centre for Biological Control, Department of Zoology and Entomology, Rhodes University, P.O. Box 94, \\ Grahamstown 6140, South Africa; julie.coetzee@ru.ac.za \\ 2 South African National Biodiversity Institute, KwaZulu-Natal Herbarium, Berea Road, Durban, \\ P.O. Box 52099, Durban 4007, South Africa; M.Nxumalo@sanbi.org.za (M.M.N.); R.Lalla@sanbi.org.za (R.L.); \\ N.shabalala@sanbi.org.za (N.S.) \\ 3 Centre for Biological Control, Department of Botany, Rhodes University, P.O. Box 94, \\ Grahamstown 6140, South Africa; g.martin@ru.ac.za \\ * Correspondence: m.ndlovu@ru.ac.za; Tel.: +27(0)46-603-7706 or +27-746920257
}

Received: 25 February 2020; Accepted: 4 April 2020; Published: 21 May 2020

check for updates

\begin{abstract}
Sagittaria platyphylla Engelm. (Alismataceae) is a freshwater aquatic macrophyte that has become an important invasive weed in freshwater systems in South Africa, New Zealand, Australia, and recently China. In South Africa, due to its rapid increase in distribution and ineffective control options, it is recognised as one of the country's worst invasive aquatic alien plants. In this paper, we investigate the spread of the plant since its first detection in 2008, and the management strategies currently carried out against it. Despite early detection and rapid response programmes, which included chemical and mechanical control measures, the plant was able to spread both within and between sites, increasing from just one site in 2008 to 72 by 2019. Once introduced into a lotic system, the plant was able to spread rapidly, in some cases up to $120 \mathrm{~km}$ within 6 years, with an average of $10 \mathrm{~km}$ per year. The plant was successfully extirpated at some sites, however, due to the failure of chemical and mechanical control, biological control is currently being considered as a potential control option.
\end{abstract}

Keywords: freshwater macrophyte; invasive species; mechanical and chemical control; biological control

\section{Introduction}

Invasive alien plants pose one of the greatest threats to the world's biodiversity, ecosystem services, and economic costs [1-4]. Invasive aquatic macrophytes are no exception and are among the world's most damaging and problematic species. They cause harm by altering ecosystems, out-competing native species for resources and altering genetic diversity [5,6]. Since the early 1900s, South Africa's freshwaters systems have been invaded by a number of aquatic macrophytes, which have had detrimental economic and environmental effects $[7,8]$. The worst of these include water hyacinth (Pontederia crassipes Mart. (Pontederiaceae)), parrot's feather (Myriophyllum aquaticum (Vell.) Verdc. (Haloragaceae), giant salvinia (Salvinia molesta D.S. Mitchell (Salviniaceae)), water lettuce (Pistia stratiotes L. (Araceae)), and red water fern (Azolla filiculoides Lam. (Azollaceae)) which comprised the 'Big Bad Five' water weeds [5,9-11]. Since the 1960s, various chemical, mechanical, and biological control programmes have been implemented against these weeds and the majority are now regarded as being under complete control [12]. Recently, several lesser-known floating, submerged, and emergent species have been identified in South African freshwater systems including Sagittaria platyphylla Engelm. 
(Alismataceae), commonly known as Delta arrowhead. Unlike the 'Big Bad Five' already under control in South Africa, very little is known about these species including current distribution, modes of spread and best management practice [9].

Sagittaria platyphylla, an emergent aquatic macrophyte that can take on a submerged form, is native to ponds, lakes and slow-moving streams of south-central United States of America [13,14] (Figure 1a). However, it has become invasive in Russia, Indonesia, Panama, New Zealand, Australia, and most recently in South Africa and the Yangtze River basin in China [15,16]. Naturalised populations of the plant were discovered in South Africa in 2008, where its escape is assumed to be the consequence of unintentional introduction via dumping of fish tank contents and in trout hatcheries [16,17], and it is now regarded as one of the fastest spreading invasive species in the country [10]. The plant's ability to reproduce sexually and asexually contributes to its rapid rate of spread. Each S. platyphylla plant produces numerous inflorescences every few weeks, with approximately 70,000 achenes per inflorescence $[15,18]$. Therefore, even a small population of S. platyphylla produces hundreds of thousands of viable achenes every few weeks. Achenes disperse to new sites via wind and water, and as hitchhikers on recreational equipment and water birds [10]. Asexual reproduction occurs via vegetative propagules, such as underground stem fragments, daughter plants (runners), stolons and tubers $[10,18]$. The underground tubers allow the plant to survive through drought, water drawdown, frost and chemical and mechanical management [10]. This was demonstrated by [18], who showed that reduced above surface biomass stimulated tubers and submerged plants grow into emergent plants due to reduced competition. The rapid spread of S. platyphylla since its arrival in South Africa is particularly worrying because of the negative impacts associated with its occurrence in aquatic systems in other countries, particularly Australia [10,19,20].

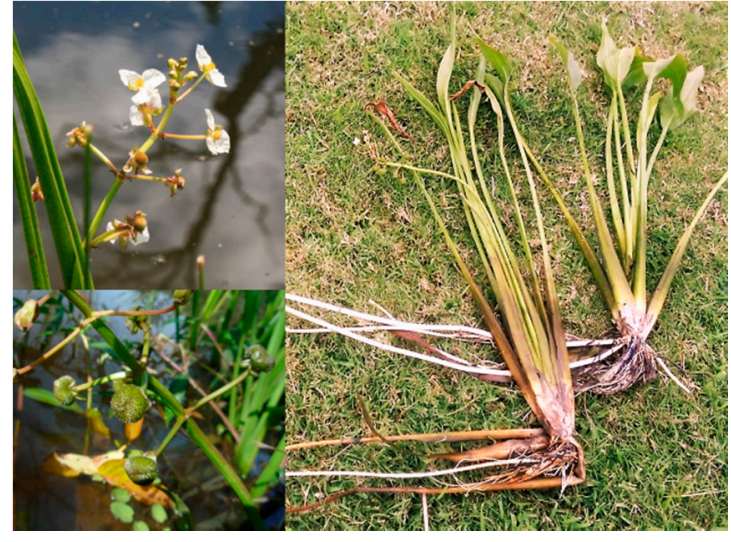

(a)

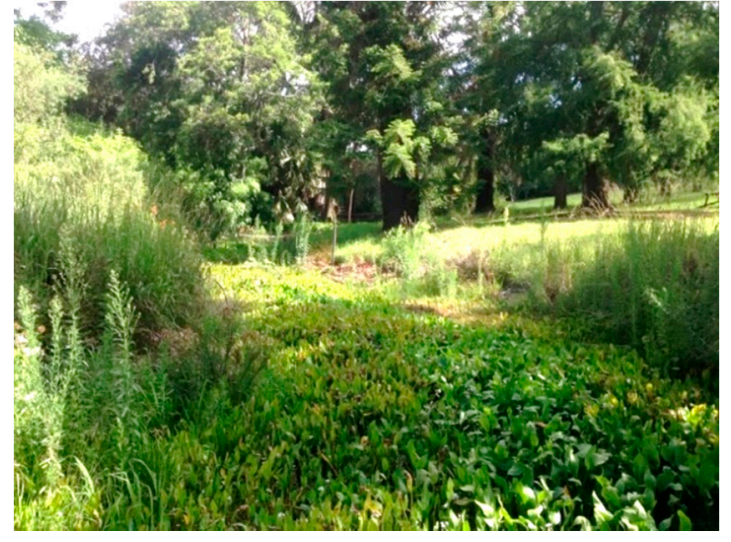

(b)

Figure 1. (a) Sagittaria platyphylla raceme (top left), fruit (bottom left) and whole plant showing roots system and stolons (right). (b) Dense monoculture of S. platyphylla choking stream in Makana Botanical Gardens, Grahamstown, Eastern Cape Province, South Africa (32.7369 S; 27.2993 E).

Sagittaria platyphylla is considered a Weed of National Significance in Australia, where it invades irrigation channels/canals and drains, forming dense monocultures that impede water flow, increasing risk of flooding and damaging irrigation infrastructure $[19,21]$. At least AUS \$2 million is spent annually attempting to manage the weed $[19,22]$, but most of these control mechanisms have been ineffective [10]. Herbicide applications currently used in irrigation channels in Australia only provide short-term control $[19,23]$. In some locations, winter dewatering and/or mechanical excavation are also used, but these methods can be difficult to manage, are costly, and may not achieve the desired level of management as they are not consistent between locations and time of application [10,24]. Currently there are no biological control options using host specific natural enemies against the weed, 
however research programmes to identify and test potential agents are underway in both Australia and South Africa [16,22].

Several management options are used to control invasive macrophytes in South Africa, with varied success, often requiring integrated control to obtain acceptable results [8]. Small infestations of macrophytes may be removed manually, or mechanically using specialised harvesters, but this is labour intensive, requiring frequent follow-up treatments because not all plants are removed, allowing regeneration of the infestation via vegetative reproduction. The herbicide glyphosate is most widely used to control aquatic invasives, but it is not recommended for the floating species under effective or complete biological control (viz. P. stratiotes, S. molesta, M. aquaticum, and A. filiculoides) as this could interfere with the level of control achieved through biological control alone (8). In South Africa, weed management strategies are primarily driven by government legislation, where the National Environmental Management: Biodiversity Act (NEM: BA) (Act no.10 of 2004), provides a framework for assessment, listing, and management of invasive species. Under the regulation, invasive plant species under Category 1(a) are mainly assigned herbicide application, mechanical and manual removal with the aim of eradicating the species. Invasive plants listed as 1(b) are those that cause considerable environmental and/or economic damage, but have spread to such an extent that the likelihood of eradicating the species is negligible and therefore the goal is to manage the species and not focus on eradication [25].

Since its establishment in South Africa, S. platyphylla was listed as a Category 1(a) species, and is therefore a target for eradication using mechanical and chemical control. Here we aim to evaluate the spread of S. platyphylla and the success of management strategies implemented against the weed in South Africa, which may assist in its future management or give insight to the management of similar species still in their early stages of invasion.

\section{Materials and Methods}

Sagittaria platyphylla was first discovered in South Africa in a mountain stream, located in the Krantzkloof Nature Reserve, KwaZulu-Natal Province (29.7727 S; 30.83086 E) in 2008. Thereafter quantitative surveys of the weed population and any newly detected populations were conducted in the Eastern coastal provinces (viz. KwaZulu-Natal, Eastern Cape and Western Cape provinces) by different stakeholders which included government and research institutions from 2008 to 2019. The majority of surveys were conducted in the summer of each year, during the plant's flowering season. The datasets were combined, cleaned, and standardized in order to meet this study's objectives.

To determine whether S. platyphylla was more widespread than the first infestation recorded and to be able to determine spread, surveys were conducted below and above the infestations, as well as at all closely surrounding water systems, to identify additional infestations. New sites were treated as new populations. When new populations were recorded, the same process was followed to identify surrounding populations. At each site, the following was recorded: survey date, location, longitude and latitude, water body type (lentic or lotic water system), population size, and plant density. Population size was estimated by determining the length and width of the population $\left(\mathrm{m}^{2}\right)$, while plant density at each site was measured by randomly placing 10 quadrats $\left(1 \mathrm{~m}^{2}\right)$ at each site and counting the number of plants in each. During the compilation of the dataset, the annual mean value of population size and plant density were recorded for each site. To normalize the data, sites with visually estimated plant density and population size were assigned plant density values, and sites with population length as the estimated population size were assigned population width to calculate the population size in $\mathrm{m}^{2}$ (Table 1 ). 
Table 1. Classification of Sagittaria platyphylla population size and plant density.

\begin{tabular}{cc}
\hline $\begin{array}{c}\text { Population Size in } \mathbf{~ m}^{\mathbf{2}} \text { (Infestation Length: } \\
\text { Assigned Diameter) }\end{array}$ & $\begin{array}{c}\text { Plant Density (Number of Plants } / \mathbf{m}^{2} \text { ): } \\
\text { Assigned Plant Density Values * }\end{array}$ \\
\hline$>450 \mathrm{~m}: 4 \mathrm{~m}$ & $>75$ plants $/ \mathrm{m}^{2}: 95$ plants $/ \mathrm{m}^{2}$ \\
$205-450 \mathrm{~m}: 3 \mathrm{~m}$ & $45-75 \mathrm{plants} / \mathrm{m}^{2}: 65$ plants $/ \mathrm{m}^{2}$ \\
$50-250 \mathrm{~m}: 2 \mathrm{~m}$ & $15-45$ plants $/ \mathrm{m}^{2}: 35$ plants $/ \mathrm{m}^{2}$ \\
$<50 \mathrm{~m}: 1 \mathrm{~m}$ & $<15$ plants $/ \mathrm{m}^{2}: 5$ plants $/ \mathrm{m}^{2}$ \\
\hline
\end{tabular}

${ }^{*}$ Data standardization used to assign plant density with estimated plant density values.

To map the change in the distribution of S. platyphylla over the surveyed years, the Geographic Information System (GIS) software, ArcGIS 10.5.1. (ESRI: Redlands, CA, United States) was used to transform the distribution data into a digital map with number of sites recorded annually. The distribution map was narrowed down to three invaded provinces (KwaZulu-Natal, Eastern Cape and Western Cape provinces). The longest invaded lotic water system in each province was singled out to estimate the spread of infestation over the years. Additionally, a general linear model with Poisson errors and a log link function was conducted in R version 3.6.0 (R Core Team: Auckland, New Zealand) to determine whether the number of S. platyphylla sites identified in South Africa increased over time, by determining the relationship between time in years and the number of sites recorded every year.

To visualize the change in S. platyphylla's population demographics over the surveyed years, the trend over time of the overall population size and plant density of infestations were evaluated by grouping population size and plant density values recorded for each year into categories ranging from smallest to largest for each province (KwaZulu-Natal, Eastern Cape and Western Cape provinces) (Table 2). During the surveys, sites where control had been attempted were assigned a qualitative measure: 'extirpated' sites where complete removal of the population through control methods was achieved for a period longer than three years; 'attempted control' sites in which the weed persisted in spite of the control method applied; 'not controlled' sites where no control was applied. A negative binomial general linear model was conducted to determine whether the population size and plant density changed significantly over time, by determining the relationship between time in years and the average population size and plant density recorded every year.

Further, the management cost spent on controlling infested sites was compiled from data supplied by South African National Biodiversity Institute (SANBI), private landowners and research costs of the Centre for Biological Control, Rhodes University. The management techniques used for managing S. platyphylla across invaded sites were evaluated to determine their effectiveness. Herbicide control involved spraying Kilomax (glyphosate based) on emergent plants, and manual and mechanical control of S. platyphylla involved extracting seedlings and smaller plants by machinery or manual digging, bagging the plant material, and burning it (Private landowners Pers. comm). To give an overall indication of management sites under similar eradication techniques (herbicide, manual, and mechanical control), sites were grouped together for each province to determine the outcome of the control mechanisms used.

Table 2. Population size and plant density categories of Sagittaria platyphylla sites.

\begin{tabular}{ccc}
\hline Population Category & Population Size $\left.\mathbf{( m}^{\mathbf{2}}\right)$ & Plant Density (Plant $\left./ \mathbf{m}^{\mathbf{2}}\right)$ \\
\hline Extirpated sites * & - & - \\
Temporarily cleared sites $\$$ & 0 & 0 \\
Small & $5-100$ & $5-35$ \\
Medium & $100-500$ & $35-65$ \\
Big & $500-1000$ & $65-95$ \\
Large & $>1000$ & $>95$ \\
\hline
\end{tabular}

* Sites cleared for more than the past three years; ${ }^{\$}$ sites cleared for less than two years. 


\section{Results}

\subsection{Current Distribution of S. platyphylla in South Africa}

The first recorded site of S. platyphylla in South Africa was in Krantzkloof Nature reserve in KwaZulu-Natal Province in 2008. Between 2009 and 2010, eight more sites were recorded, including; Jonkershoek Trout Hatchery (33.96283 S; 18.9261 E) and Paarl Sewage Works (33.68417 S; 18.98361 E) in the Western Cape Province; Makana Botanical Gardens, Grahamstown (32.7369 S; 27.2993 E) (Figure 1b) and Maden Dam (33.3156 S, 26.5209 E) in the Eastern Cape Province, and Ascot Bush Lodge, (29.6011; 30.409) in KwaZulu-Natal Province. Over the next 10 years, the infestation spread within and between sites in South Africa.

The cumulative number of $S$. platyphylla sites recorded per year in South Africa resulted in a significant increase in number of sites over the years $\left(F_{-1,10}=0.222, P=0.001\right.$ ) (Figure 2a) with an annual significant increase in population size $\left(F_{1,10}=0.109, P=0.003\right)$ (Figure $2 \mathrm{~b}$ ). There was no significant difference in plant density measured over the years $\left(F_{1,10}=0.028, P=0.476\right)$ but the trend revealed a gradual increase in plant density from 2008 to 2016 followed by a sudden decrease from 2016 to 2019 since first record of invasion (Figure 2c). There are now 72 known sites, distributed through the three coastal provinces (Figure 3). The weed has primarily invaded lotic water systems, with $80 \%$ of sites in lotic systems, compared to $20 \%$ in lentic systems. Most sites were located in slow-moving water bodies such as the Molweni and Umgeni Rivers in KwaZulu-Natal Province and the Berg River, Western Cape Province.

(a)

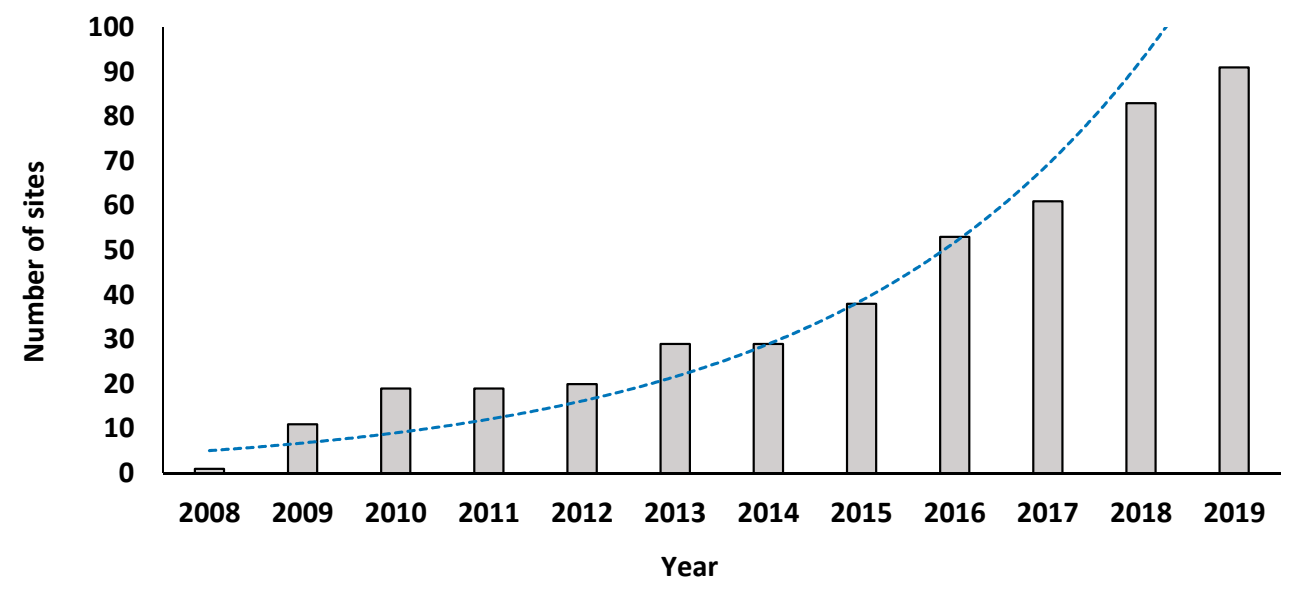

(b)

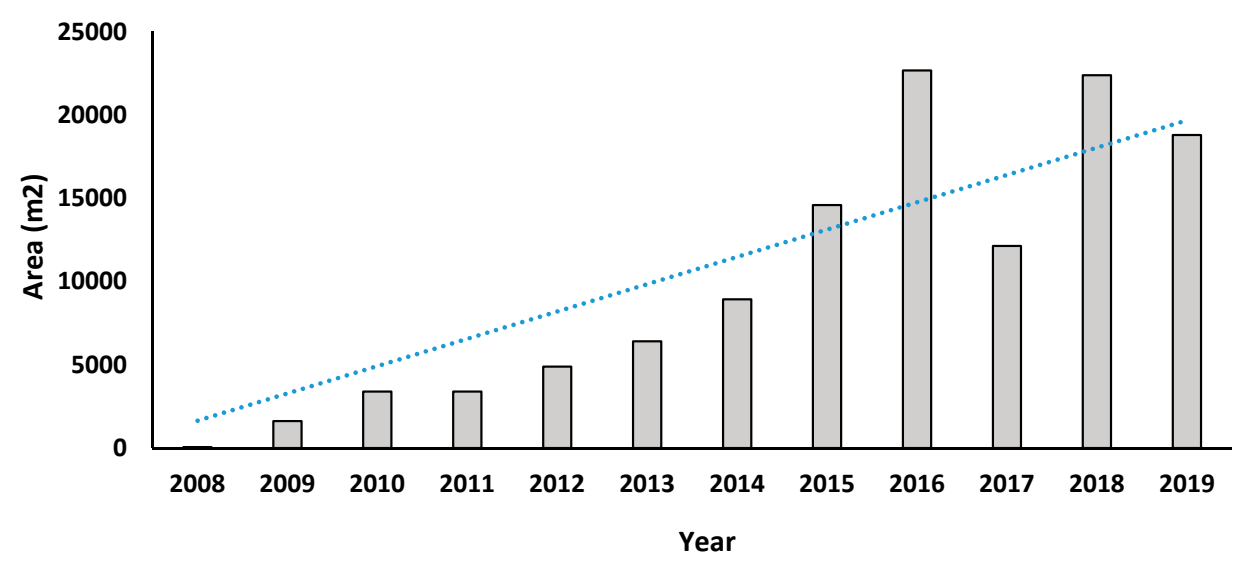

Figure 2. Cont. 
(c)

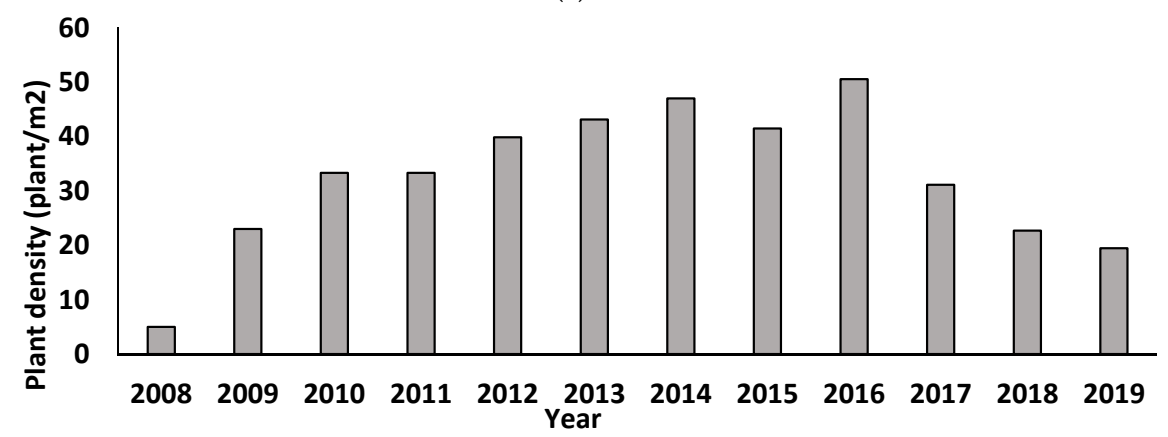

(d)

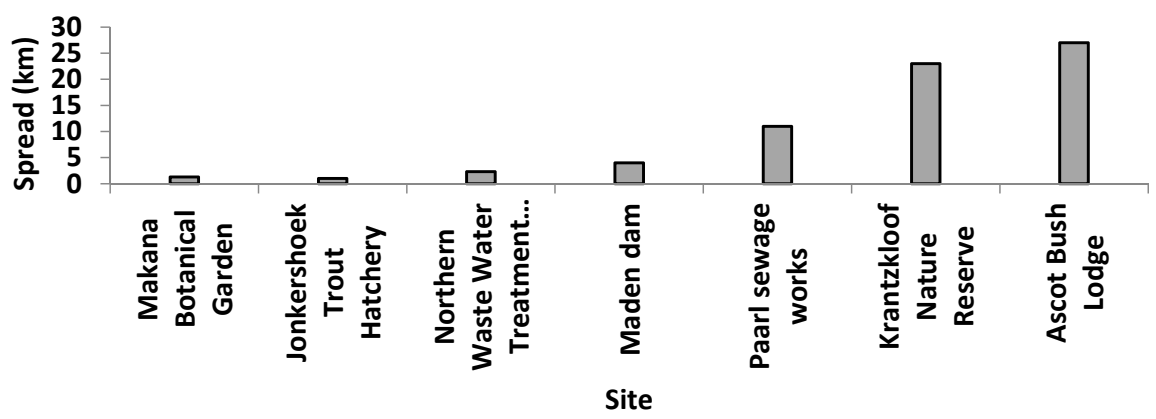

Figure 2. (a) Significant increase in cumulative number of Sagittaria platyphylla sites recorded per year in South Africa (GLM; $\left.F_{1,10}=0.222, P=0.001\right)$. (b) Significant increase in mean population size of S. platyphylla per year in South Africa (GLM.NB; $F_{1,10}=0.109, P=0.003$ ). (c) Mean plant density of S. platyphylla per year in South Africa (GLM.NB; $\left.F_{1,10}=0.028, P=0.476\right)$. (d) The spread $(\mathrm{km})$ of S. platyphylla from the most invaded populations since 2008.

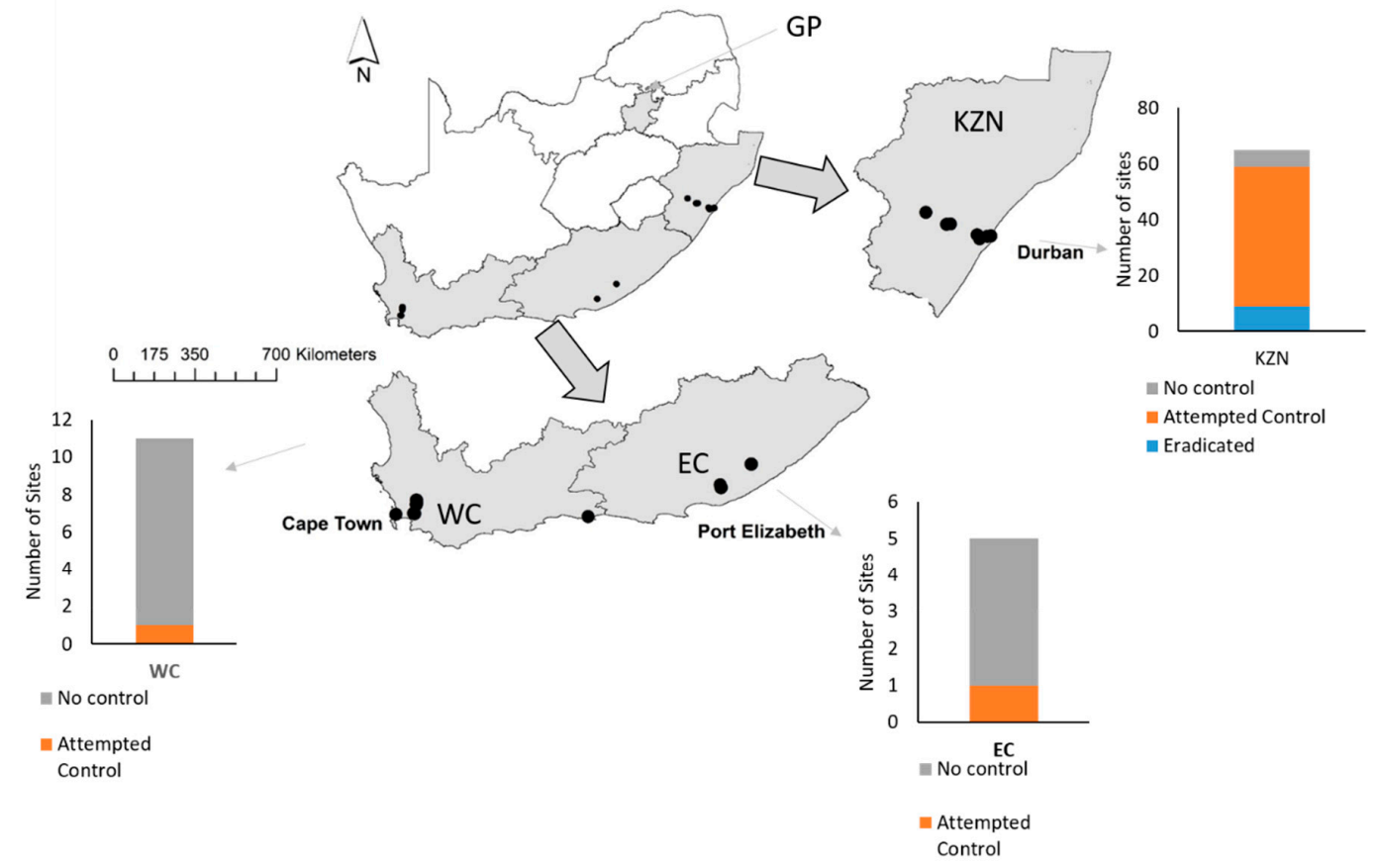

Figure 3. Sagittaria platyphylla localities (black dots) in South Africa in 2019. Gauteng (GP), KwaZuluNatal (KZN), Eastern Cape (EC) and Western Cape (WC). Bars depict management attempts of the number of sites infested with S. platyphylla in KwaZulu-Natal (KZN), Eastern Cape (EC), Western Cape (WC), under different management techniques (herbicide application, manual and mechanical removal). 
In KwaZulu-Natal, the infestation in the Umgeni catchment, one of the most important catchments in the province, has spread $120 \mathrm{~km}$ over the 10 years (Ascott Bush lodge and Krantzkloof Nature reserve are both in the system). In the Eastern Cape Province, the weed has spread downstream $6.6 \mathrm{~km}$ from Maden Dam. Additionally, in the Eastern Cape Province, the weed has spread $1.3 \mathrm{~km}$ downstream from the Makana Botanical Garden, since it was first recorded in 2009. In the Berg River, Western Cape Province the plant has spread $13.1 \mathrm{~km}$ downstream since it was first recorded in 2009.

Sagittaria platyphylla population size and density in South Africa increased gradually over time since the first invasion record. After 2013, these data were influenced by control efforts within the sampled years. From the point of introduction until 2019, there was a steady increase in the number of small-sized populations, ranging between 5 and $100 \mathrm{~m}^{2}$ and medium-sized populations between 100 and $500 \mathrm{~m}^{2}$ (Figure 4). In 2013, sites with larger population sizes $\left(>1000 \mathrm{~m}^{2}\right)$ were recorded, and by 2015 , population sizes ranging between 500 and $1000 \mathrm{~m}^{2}$ were also recorded (Figure 4). By 2016, the extent of the invasion was at its highest, covering an infestation area of $22,685 \mathrm{~m}^{2}$ from a total of 33 sites, with population sizes ranging between 100 and $500 \mathrm{~m}^{2}$, dominating the infestations. Additionally, two sites were successfully eradicated through control efforts (Kingfisher Lake, Pietermaritzburg (29.605 S; 30.348 E) and the Japanese Garden, Pinetown (29.835 S; 30.871 E), both in KwaZulu-Natal Province). In 2017, the number of sites with population sizes ranging between 100 and $1000 \mathrm{~m}^{2}$ decreased, while the number of sites with smaller population sizes ranging between 5 and $100 \mathrm{~m}^{2}$ increased. Additionally, the number of eradicated sites increased by six, and the number of temporarily cleared sites started to be recorded. Between 2016 and 2018, the invaded area decreased slightly from 22,685 to $22,396.48 \mathrm{~m}^{2}$, but in the same period the number of sites increased from 33 to 54 . Over the entire period, the most commonly encountered sites fell in the 5 to $100 \mathrm{~m}^{2}$ size range. The number of sites with large population size $\left(>1000 \mathrm{~m}^{2}\right)$ gradually increased while the number of sites with population sizes ranging between 100 and $1000 \mathrm{~m}^{2}$ continued to decrease from the previous year. Additionally, the number of eradicated sites increased by seven, and the number of temporarily cleared sites gradually increased, while no new eradicated sites were recorded. In 2019, the population size continued to drop from the previous year to $18,804 \mathrm{~m}^{2}$ but the number of sites continued to increase (Figure 4a).

(a)

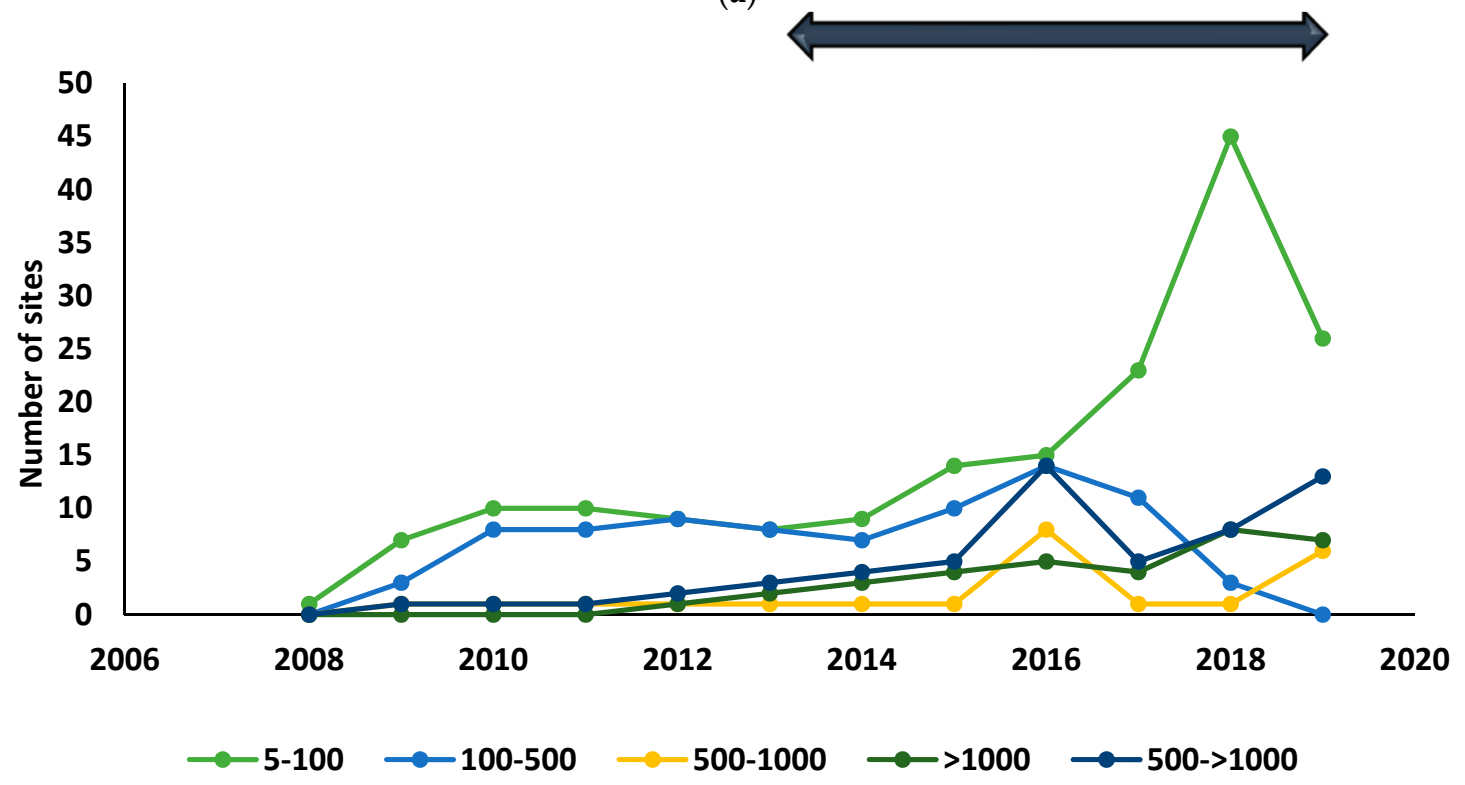

Figure 4. Cont. 
(b)

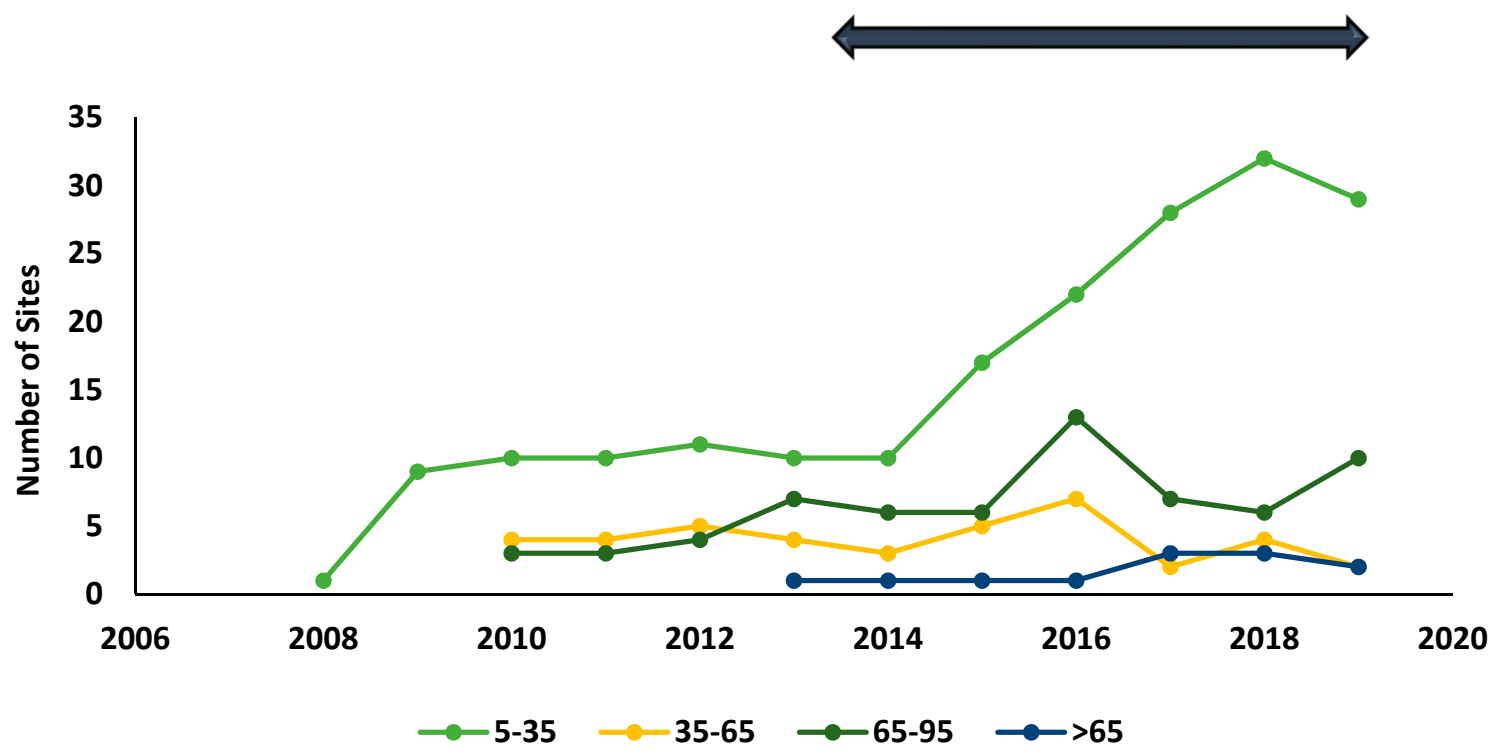

Figure 4. The extent of Sagittaria platyphylla infestations in South Africa from 2008 to 2019, categorised as the total number of sites with a particular population size category (a) and plant density (b) recorded each year. The black arrow across the top indicates the initiation of management options, including mechanical and chemical control.

The plant density within populations followed a similar pattern as population size, with plant density slowly increasing from 2008 to 2015, with the highest peak in 2016 of 51 plant $/ \mathrm{m}^{2} \pm 0.86$ S.E., then the trend changed in 2016 and started fluctuating until 2019 (Figure 4b). Populations in the country are mostly dominated with plant density of 5 to 35 plants $/ \mathrm{m}^{2}$.

\subsection{Management in South Africa}

The total management cost spent on S. platyphylla in South Africa from 2010 to 2019 was estimated to be ZAR 1,720,000 (US $\$ 118,388$ ) (Table 3). The biggest items on the budget were herbicides and salaries of local contractors employed to spray and, where appropriate, manually remove S. platyphylla populations. As no biological control agents have been released yet, no comparison could be made with regard to the cost incurred vs. management, but the cost spent on the research for the weed's biological control was included.

Table 3. The total management cost of Sagittaria platyphylla in South Africa from 2010 to 2019.

\begin{tabular}{ccccc}
\hline Organisation & Type of Control & Time Frame & Overall Management Cost (R) & US\$ (1R = \$0.07) \\
\hline Government (SANBI-BID) & Mechanical/Chemical & $2010-2019$ & $1,000,000$ & 60,000 \\
NGO & Chemical & $2013-2017$ & 600,000 & 4286 \\
42,857 & 4286 & 118,000 & $1,720,000$ \\
Private Landowner 1 & Mechanical/Chemical & $2017-2019$ & 2016 & 701,000 \\
Private Landowner 2 & Mechanical & & & 50,071 \\
\hline Total Cost & & $2013-2019$ & \\
\hline Government & Biological Control & &
\end{tabular}

For the control of S. platyphylla in South Africa, the eradication efforts by SANBI BID (South African National Biodiversity Institute- Biological Invasions Directorate) were almost entirely implemented in KwaZulu-Natal Province, where nine sites were recorded as extirpated, 51 sites remained present after eradication attempts and six sites were recorded as not being under any form of management. In the Eastern Cape Province, eradication was attempted at only one site (Maden Dam: 32.748 S; 
27.297 E), while three sites were not under any form of management. In the Western Cape Province, one site (33.954 S; $18.910 \mathrm{E}$ ) was mechanically controlled by a private landowner in 2016, but this was unsuccessful as the weed returned the following year. Finally, the only infestation in Gauteng Province, first recorded in 2009 (Pretoria National Botanical Gardens: 25.739 S; 28.272 E), was extirpated by SANBI BID in 2013 through manual control. Sites that were cleared due to natural processes (draught and floods) were not included in the successful eradication count. In summary, in 2019, following six years of management, 64 sites were actively managed, but only 10 of the 64 were successfully extirpated. Even though there were some extirpated sites, there was a general increase in the total area covered by S. platyphylla, as well as the number of larger population size which increased 3.8 times more (Figure 5). In 2013, when eradication techniques were initiated by SANBI BID, S. platyphylla infestations covered a total area of $3035 \mathrm{~m}^{2}$, at a cost of ZAR 32.95 (US\$2.21)/ $\mathrm{m}^{2}$, but by 2019 the infestation cover had increased to $9847 \mathrm{~m}^{2}$ and the number of sites from 19 to 70 , therefore only ZAR 10.16 (US $\left.\$ 0.68\right) / \mathrm{m}^{2}$ was available for management.

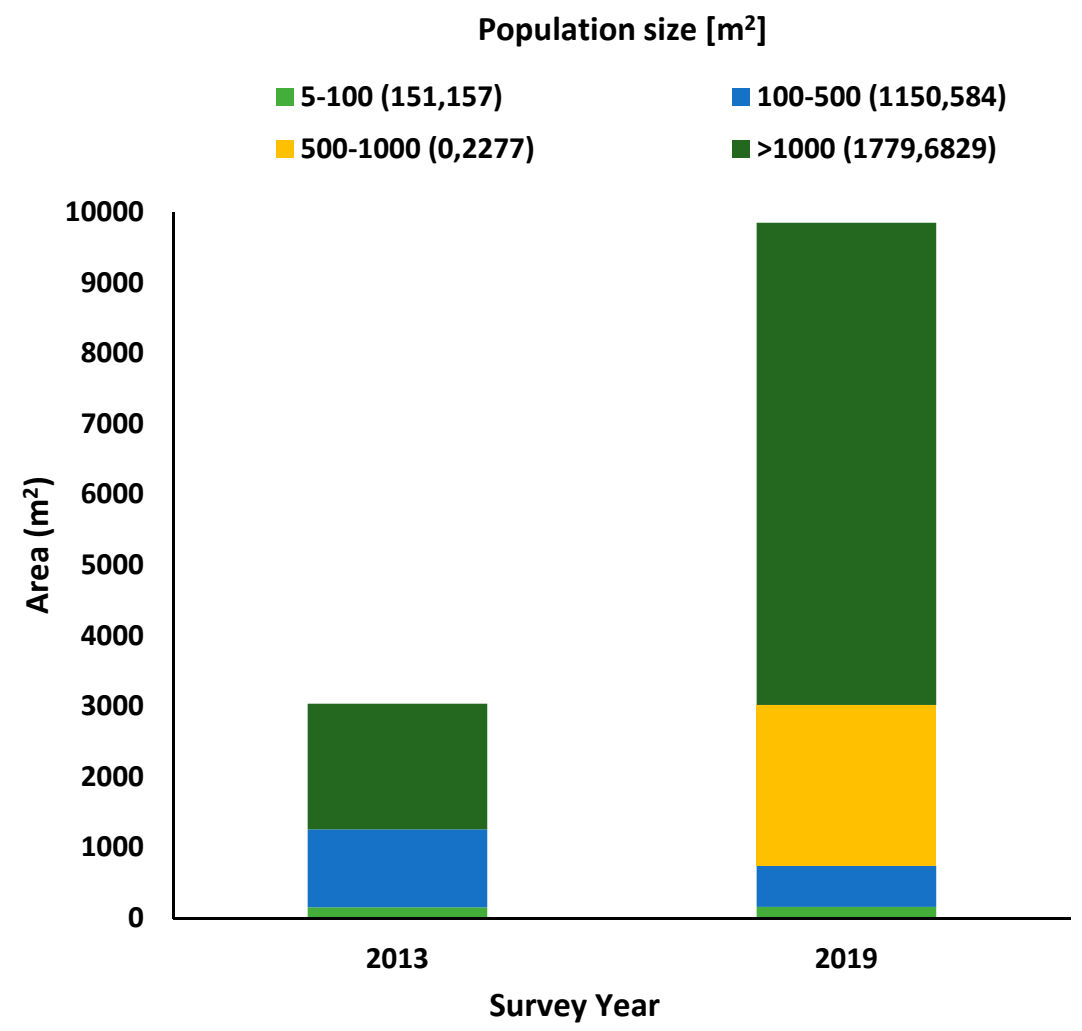

Figure 5. The area occupied by Sagittaria platyphylla infestation composed of different population sizes in South Africa at the initiation of eradication control project in 2013, and after six years of eradication application in 2019. Population size range from small (5-100), medium (100-500), big (500-1000) and large $(>1000)$.

\section{Discussion}

The results presented here on the spread of S. platyphylla within and between freshwater systems in South Africa since its first identification in 2008, and the eradication approaches that were attempted against the weed, form an important case study for invasive aquatic plant control. To date, despite significant financial investment, S. platyphylla continues to spread exponentially with invasions becoming more widespread and abundant. The invasion in South Africa is at the stage where eradication is no longer a feasible option.

In invasive species management, early detection and rapid response are usually key to successful control [2]. This is intuitive as the smaller and more localised the infestation, the more resources can be 
targeted to ensure that control is achieved. As invasions become larger, finances and resources become increasingly diluted and eradication becomes less likely [2]. An excellent example of substantial control in South Africa is the successful management of Spartina alterniflora Loisel. (Poaceae), an aggressive ecosystem engineer. The small population of the plant ( $<1 \mathrm{ha}$ ) was first detected in the Great Brak Estuary, Western Cape Province, in 2004, and through regular herbicide treatment during the growing period, the plant was successfully extirpated [26]. The success of this programme was attributed to the small, accessible localised infestation, and appropriately timed herbicide application [26]. When responding to new plant invasions, two key practices are essential to ensure eradication. Firstly, plant removal and/or destruction must be greater than population growth; and secondly, management must be continued until no more propagules are present within the system [2]. This is often a challenge in most invasion cases, resulting in a waste of resources, and more importantly, failed eradication attempts, as experienced with S. platyphylla management in South Africa.

Sagittaria platyphylla has a number of morphological and reproductive traits which make its management difficult. Outside of its native range, and especially in more subtropical environments such as South Africa, S. platyphylla is able to produce high numbers of achenes as well as underground tubers continuously throughout the year, so that fruiting and plant growth is not limited to a single season. In these areas, $S$. platyphylla is able to continuously produce sexually mature plants capable of producing thousands of viable seeds [18]. Management must therefore be implemented almost continuously to ensure no plants reach maturity. In South Africa, once the plant had escaped from its initial points of invasion, occurring in high densities in lentic systems, this kind of intensive management became impossible. The sheer number of continuously produced achenes allows rapid repopulation of a system after management if a single plant remains. The achenes are also easily transported within and between systems, making containment of populations nearly impossible. The underground tubers also allow the plant to survive drought, water drawdown, frost, and chemical and mechanical management [10]. Management has to consider how to remove these propagules or how to manage them once they grow into emergent plants again capable of setting seeds. In South Africa, the removal of below-ground tubers was not attempted, as management focused on emergent plants, allowing regeneration from the tubers [27].

In addition, the ecological requirements of $S$. platyphylla may influence its management. In the USA, S. platyphylla has broad ecological tolerance, but is generally restricted to warm-temperate regions [1], in South Africa it is able to thrive in both the warm sub-tropical climates of KwaZulu-Natal and the cooler Mediterranean climate of the Western Cape Province. In cooler regions, frost may kill or damage mature plants, but regrowth occurs from submerged plants or tubers [1]; overhanging vegetation may also protect plants from frost, allowing them to continue flowering throughout winter. To date, the plant has only been recorded from a single site in the interior of the country, Pretoria National Botanical Gardens, Gauteng Province (25.739 S: 28.272 E), but it was quickly and easily eradicated. It is currently not known if the interior of South Africa will be as suitable as the coastal regions. Sagittaria platyphylla is also not limited by type of water system as it has invaded large lotic systems such as the Berg and Umgeni river systems; ruderal habitats such as irrigation supply channels; drainage ditches; and artificial impoundments (small ornamental lakes, sewerage and fisheries ponds [12]. It also tolerates high salinities as it has been recorded from the Beachwood Mangrove Swamp (29.790 S: 31.047 E) in Durban, KZN. Water depth, which seems to limit the species in the USA, is also not currently limiting the species in South Africa [28 with the plant being recorded growing in water deeper than $2 \mathrm{~m}$. Finally, escape from its natural enemies in its native range has allowed S. platyphylla to invest in reproductive outputs [20]. Ref [12] showed that plants in growing in South Africa had $40 \%$ more achenes per fruiting body, and also weighed 50\% more, compared to the native range. Management is therefore very difficult as the plant has a broad ecological range in which it is able to survive and dominate.

In Australia, where herbicide has been used to manage the plant for a number of decades, the application of glyphosate is the best management option, with very few other herbicidal options 
currently being used. When glyphosate is applied at label rates recommended by the manufacture, it is capable of killing emergent S. platyphylla plants, but there is rapid regrowth from tubers $[19,22]$, as the submerged form of the plants survive, and the underground tubers are not affected by the application of foliar spray herbicides [19]. Applying higher quantities (up to 10 times the label rate) is reported to be more effective, but results are variable, and regrowth still occurs [18,22,28,29]. Further, herbicide application above the specified levels in aquatic ecosystems is not recommended. When the incorrect dosages are applied to target plants, they result in build-up of residue from additives that can be harmful to the environment [10,16], threatening human and animal health [30]. Because of the negative environmental impacts, the use of glyphosate is banned in European agriculture [31]. Currently there is concern in Australia about possible herbicide resistance developing within the S. platyphylla populations which may influence future management strategies [22].

In South Africa, Arysta Life Science (2011) initiated field trials using Kilomax and Diquat herbicides, which are recommended for aquatic species [32]. Kilomax (glyphosate based) mainly attacks emergent and floating plants, while Diquat kills submerged plants [3]. Kilomax applied to S. platyphylla causes the plant to decay from the base, leaving unsightly infested areas, especially restricted areas such as ornamental ponds (personal observation). Field trials resulted in initial suppression of S. platyphylla, which was however, followed by regrowth [28]. Based on the results of long-term monitoring of the sites across South Africa, herbicides have not been successful in the eradication of S. platyphylla but may have reduced infestations in certain areas. Mechanical excavation has also been attempted to manage and extirpate populations in Australia. This method is regarded as labour intensive, requiring great effort to produce effective results, because successfully removing all subterranean propagules from any population larger than a hectare is most likely not possible $[10,22]$. However, there is no evidence to show that manual and mechanical control has been effective for large populations. There is also a high risk associated with manual and mechanical control of S. platyphylla, as remaining broken plant fragments, floating seeds, and underground tubers have the ability to regenerate and quickly re-infest systems [28]. In South Africa and Australia, extirpation was only possible for small infestations in very small systems where the entire infestation was accessible [22]. Once S. platyphylla has established within a freshwater ecosystem, it is very difficult to eradicate, and management should switch from eradication-based management to a management strategy tailored to the requirements of the system that has been invaded.

Unfortunately, the programme against S. platyphylla in South Africa is unlikely to receive increased financial support. In 2013, approximately ZAR 32.95 (US\$2.21) $/ \mathrm{m}^{2}$ was used to manage S. platyphylla, but by 2019, the amount available had decreased to approximately ZAR 10.16 (US $\$ 0.68$ ) $/ \mathrm{m}^{2}$. It seems unlikely that eradication will be achieved in South Africa under the current management practices, given the extent of the invasion. Biological control thus far has not yet contributed to the management of the species in South Africa because potential control agents are still undergoing quarantine host-specificity testing. Surveys for natural enemies were conducted in the USA, which resulted in the collection of four Listronotus weevils as potential agents. While the cost of developing the control agents has amounted to ZAR701,000 (US\$ 50,071), once they are released, they should offer an additional environmentally friendly strategy to assist in the management of the weed if they reduce the impacts and spread of $S$. platyphylla $(16,23)$. Although biological control may not be effective in all situations, it must be considered as a tool within an integrated weed management framework $[7-9,33]$.

While eradication is possible on emergent aquatic weeds, e.g., the successful eradication of S. alterniflora from the Great Brak River, a number of factors contribute to eradication success. If the infestation is limited in distribution, and contained in a small area, persistent, and continuous chemical application under good supervision and monitoring can affect both above- and below-ground biomass, provided that sufficient funding is allocated to support the programme [2,26,34]. The eradication of S. platyphylla from South Africa is no longer an option, so the species should be re-categorised as a 1(b) species, and management should change appropriately. When new infestations of S. platyphylla are recorded, control methods should be implemented with a strong focus on containment to ensure 
the species does not become increasingly widespread and damaging in South Africa. Future studies on the economic and environmental impacts of $S$. platyphylla should be prioritised to justify the costs associated with its control. In addition, biological control may offer further options to slow the spread of S. platyphylla, as it has with the management of other aquatic weeds in South Africa, in a far more sustainable manner.

Author Contributions: Writing—original draft preparation: M.S.N. and G.D.M.; writing—review and editing: G.D.M. and J.A.C.; Data curation: M.M.N., R.L., and N.S. All authors have read and agreed to the published version of the manuscript.

Funding: This research was funded by the South African Research Chairs Initiative of the Department of Science and Technology and the National Research Foundation of South Africa. Any opinion, finding, conclusion or recommendation expressed in this material is that of the authors and the NRF does not accept any liability in this regard.

Acknowledgments: The South African Department of Environment, Forestry, and Fisheries (DEFF) are thanked for funding noting that this publication does not necessarily represent the views or opinions of DEFF or its employees. We also thank Bart Fokkens (formerly DUCT) and Paolo Candotti (Kloof Conservancy) for sighting observations and on-site monitoring of populations, as well as Zukiswa Zulu (DEA-NRM) for her inputs as part of the Sagittaria Working Group. We are grateful to all landowners who permitted access for research and management of these species.

Conflicts of Interest: The authors declare no conflict of interest.

\section{References}

1. Vitousek, P.M.; D’antonio, C.M.; Loope, L.L.; Rejmanek, M.; Westbrooks, R. Introduced species: A significant component of human-caused global change. N. Z. J. Ecol. 1997, 21, 1-16.

2. Rejmanek, M.; Pitcairn, M.J. When eradication of exotic pest is plants a realistic goal? In Turning the Tide, the Eradication of Invasive Species; Veitch, C.R., Clout, M.N., Eds.; International Union for the Conservation of Nature (IUCN): London, UK, 2002; pp. 249-253.

3. Carey, P.; Suresh, A.; SethiSabrina, J.; Cecil, L.; Rich, F. A primer on potential impacts, management priorities, and future directions for Elodea spp. in high latitude systems: Learning from the Alaskan experience. Hydrobiologia 2016, 777, 1-19. [CrossRef]

4. Vilà, M.; Espinar, J.L.; Hejda, M.; Hulme, P.E.; Jarošík, V.; Maron, J.L.; Pergl, J.; Schaffner, U.; Sun, Y.; Pyšek, P. Ecological impacts of invasive alien plants: A meta-analysis of their effects on species, communities and ecosystems. Ecol. Lett. 2011, 14, 702-708. [CrossRef] [PubMed]

5. McGeoch, M.A.; Butchart, S.H.; Spear, D.; Marais, E.; Kleynhans, E.J.; Symes, A.; Chanson, J.; Hoffmann, M. Global indicators of biological invasion, species numbers, biodiversity impact and policy responses. Divers. Distrib. 2010, 16, 95-108. [CrossRef]

6. Ceschin, S.; Ellwood, N.T.W.; Ferrante, G.; Mariani, F.; Traversetti, L. Habitat change and alteration of plant and invertebrate communities in waterbodies dominated by the invasive alien macrophyte Lemna minuta Kunth. Biol. Invasions 2020, 22, 1325-1337. [CrossRef]

7. Hill, M.P. The impact and control of alien aquatic vegetation in South African aquatic ecosystems. Afr. J. Mar. Sci. 2003, 28, 19-24. [CrossRef]

8. Hill, M.P.; Coetzee, J.A. The biological control of aquatic weeds in South Africa, current status and future challenges. Bothalia 2017, 47, 1-12. [CrossRef]

9. Coetzee, J.A.; Hill, M.P.; Byrne, M.J.; Bownes, A.A. Review of the biological control programmes on Eichhornia crassipes (C. Mart.) Solms (Pontederiacaeae), Salvinia molesta D.S. Mitch. (Salviniaceae), Pistia stratiotes L. (Araceae), Myriophyllum aquaticum (Vell.) Verdc. (Haloragaceae) and Azolla filiculoides Lam. (Azollaceae) in South Africa. Afr. Entomol. 2011, 19, 451-468.

10. Henderson, L.; Wilson, J.R. Changes in the composition and distribution of alien plants in South Africa, an update from the Southern African Plant Invaders Atlas. Bothalia 2017, 47, 1-26. [CrossRef]

11. Henderson, L.; Cilliers, C.J. Invasive aquatic plants. In Plant Protection Research Institute Handbook; Agricultural Research Council: Pretoria, South Africa, 2002; Volume 16, pp. 1-88.

12. Klein, H.A. Catalogue of the insects, mites and pathogens that have been used or rejected, or are under consideration, for the biological control of invasive alien plants in South Africa. Afr. Entomol. 2011, 19, 515-549. [CrossRef] 
13. Godfrey, R.K.; Wooten, J.W. Aquatic and Wetland Plants of South-Eastern United States; The University of Georgia Press: Athens, Greece, 1981.

14. Keener, B.R. Molecular Systematics and Revision of the Aquatic Monocot Genus Sagittaria (Alismataceae). Ph.D. Thesis, University of Alabama, Tuscaloosa, AL, USA, 2005.

15. Adair, R.; Keener, B.; Kwong, R.M.; Sagliocco, J.L.; Flower, G.E. The biology of Australian weeds 60. Sagittaria platyphylla (Engelmann) J.G. Smith and Sagittaria calycina Engelmann. Plant Prot. Q. 2012, 27, 47-54.

16. Martin, G.D.; Coetzee, J.A.; Lloyd, M.; Nombewu, S.E.; Ndlovu, M.S.; Kwong, R.M. Invaded habitat incompatibility affects the suitability of the potential biological control agent Listronotus sordidus for Sagittaria platyphylla in South Africa. Biocontrol Sci. Technol. 2018, 28, 468-485. [CrossRef]

17. Coetzee, J.A.; Hill, M.P.; Julien, M.H.; Center, T.D.; Cordo, H.A. Eichhornia crassipes (Mart.) Solms-Laub. (Pontederiaceae). In Biocontrol of Tropical Weeds Using Arthropods; Muniappan, R., Reddy, G.V., Raman, A., Eds.; Cambridge University Press: New York, NY, USA, 2019; pp. 183-210.

18. Broadhurst, L.; Chong, C. Examining Clonal Propagation of the Aquatic Weed Sagittaria Platyphylla; Rural Industries Research and Development Corporation: Canberra, Australia, 2011; Volume 1, pp. 1-32.

19. Chapman, M.; Dore, D. Sagittaria, Strategic Plan, Unpublished Report to Goulburn Murray Water, Boulburn Broken Catchment Management Authority and the Tri-State Sagittaria Taskforce; RuralPlan Pty Ltd.: Goomalibee, Australia, 2009.

20. Kwong, R.M.; Sagliocco, J.L.; Harms, N.E.; Butler, K.L.; Green, P.T.; Martin, G.D. Biogeographical comparison of the emergent macrophyte, Sagittaria platyphylla in its native and introduced ranges. Aquat. Bot. 2017, 141, 1-9. [CrossRef]

21. Kwong, R.M.; Sagliocco, J.L.; Harms, N.E.; Nachtrieb, J.G. Impacts of a Pre-Dispersal Seed Predator on Achene Production in the Aquatic Macrophyte, Sagittaria platyphylla. In Proceedings of the 21st Australasian Weeds Conference, Sydney, Australia, 9-12 September 2018; pp. 9-12.

22. Clements, D.; Dugdale, T.M.; Kwong, R.M. Developing Best Practice Management Strategies for Sagittaria in Australia. Phase 1: Current Management Practices-May 2018; Technical report for Murray Local Land Services; Agriculture Victoria Research (Agriculture Victoria, Department of Economic Development, Jobs, Transport and Resources): Bundoora, Australia, 2018.

23. Kwong, R.M. Is Delta arrowhead (Sagittaria platyphylla) a suitable target for biological control in Australia? In Proceedings of the 19th Australasian Weeds Conference, Science, Community and Food Security: The Weed Challenge, Hobart, Australia, 1-4 September 2014.

24. Flower, G.E. The Biology and Ecology of Arrowhead (Sagittaria Montevidensis Cham. Et Schlecht), a Weed in Rice in NSW. Ph.D. Thesis, Charles Sturt University, Wagga, Australia, 2004.

25. Zachariades, C.; Paterson, I.D.; Strathie, L.W.; Hill, M.P.; Wilgen, B.W. Assessing the status of biological control as a management tool for suppression of invasive alien plants in South Africa. Bothalia 2017, 47, 1-19. [CrossRef]

26. Riddin, T.; van Wyk, E.; Adams, J. The rise and fall of an invasive estuarine grass. S. Afr. J. Bot. 2016, 107, 74-79. [CrossRef]

27. SANBI. Sagittaria Platyphylla Distribution Meeting; South African National Biodiversity Institute: Durban, South Africa, 2017.

28. Forrest, L.; Kahler, M.; Van Oosterhout, E. Sagittaria and Arrowhead Factsheet. 2011. Available online: http//www.riverinaweeds.org.au/wp-content/uploads/2015/03/DPI_Sagittaria.pdf (accessed on 15 September 2018).

29. Vincent, K.R.; Friedman, J.M.; Giffin, E.R. Erosional consequence of saltcedar control. J. Environ. Manag. 2009, 44, 218-227. [CrossRef] [PubMed]

30. Hoare, D. Alien Invasive Plant Management Plan (WWW Document). 2014. Available online: https//sahris.sahra.org.za/sites/default/files/additionaldocs/09.\%20Appendix\%20H\%20-\%20Alien\% 20Invasive\%20Plant\%20Management\%20Plan_0.pdf (accessed on 10 March 2019).

31. Böcker, T.; Möhring, N.; Finger, R. Herbicide free agriculture? A bio-economic modelling application to Swiss wheat production. Agric. Syst. 2019, 173, 378-392. [CrossRef]

32. Westcott, N.; Lalla, R.; Mthimkhulu, N. Kirstenbosch Botanical Art Biennale, Early Detection and Rapid Response Programme; Veld \& Flora: Magaliesburg, South Africa, 2013; Volume 99, pp. 8-9. 
33. Barratt, B.I.P.; Moran, V.C.; Bigler, F.; Van Lenteren, J.C. The status of biological control and recommendations for improving uptake for the future. BioControl 2018, 63, 155-167. [CrossRef]

34. Maxwell, B.D.; Lehnhoff, E.; Lisa, J.; Rew, L.J. The rationale for monitoring invasive plant populations as a crucial step for management. Invas. Plant Sci. Manag. 2009, 2, 1-9. [CrossRef]

(C) 2020 by the authors. Licensee MDPI, Basel, Switzerland. This article is an open access article distributed under the terms and conditions of the Creative Commons Attribution (CC BY) license (http://creativecommons.org/licenses/by/4.0/). 